\title{
BMJ Open Violent injury predicts poor psychological outcomes after traumatic injury in a hard-to-reach population: an observational cohort study
}

\author{
$\overline{\text { Emmylou Rahtz, }{ }^{1} \text { Kamaldeep Bhui, }{ }^{2} \text { Melanie Smuk, }{ }^{2} \text { lain Hutchison, }{ }^{3} \text { Ania Korszun }{ }^{2}}$
}

To cite: Rahtz E, Bhui K, Smuk M, et al. Violent injury predicts poor psychological outcomes after traumatic injury in a hard-to-reach population: an observational cohort study. BMJ Open 2017;7:e014712. doi:10.1136/ bmjopen-2016-014712

- Prepublication history and additional material are available. To view these files please visit the journal online (http://dx.doi.org/ 10.1136/ bmjopen-2016-014712).

Received 12 0ctober 2016 Revised 30 January 2017 Accepted 20 March 2017

CrossMark

\section{${ }^{1}$ European Centre for}

Environment and Human Health, University of Exeter, Truro,

Cornwall, UK

${ }^{2}$ Centre for Psychiatry, Barts and The London School of Medicine and Dentistry, London, UK

${ }^{3}$ Oral and Maxillofacial Surgery, St Bartholomew's and The Royal London Hospital, London, UK

Correspondence to

Ania Korszun;

a.korszun@qmul.ac.uk

\section{ABSTRACT}

Background People who experience physical trauma face a range of psychosocial outcomes. These may be overlooked by busy clinicians. While some risk factors are understood, understanding of the psychological effects of violent injury remains limited, particularly in UK settings. This study compared psychological outcomes following interpersonal violence and accidental injury, including the persistence of psychological distress.

Methods A questionnaire survey was carried out at two time points of patients admitted to a large teaching hospital in London between July 2012 and April 2014. Participants were consecutive adult patients admitted to the Royal London Hospital with traumatic injuries, with 219 participants at baseline. Follow-up survey was 8 months later $(n=109)$. Standardised measures assessed posttraumatic stress symptoms (PTSS) (Acute Stress Disorder Scale and PTSD Checklist) and depressive symptoms (Hospital Anxiety and Depression Scale).

Results PTSS and depressive symptoms affected $27 \%$ and $33 \%$, respectively, at baseline. At 8 months, $27 \%$ and $31 \%$ reported these symptoms for PTSS and depressive symptoms, respectively. The repeated measures were assessed with multilevel models: after adjusting for demographic factors, patients with violent injury showed more PTSS (OR 6.27, 95\% $\mathrm{Cl} 1.90$ to 20.66) and depressive symptoms (OR $3.12,95 \% \mathrm{Cl} 1.08$ to 8.99 ). Conclusions There were high levels of psychological distress among traumatic injury patients. Violent injuries were associated with an increased risk of both posttraumatic and depressive symptoms. People vulnerable to distress would benefit from psychological support, and hospital admission provides a unique opportunity to engage hard-to-reach groups in interventions.

\section{INTRODUCTION}

Violence and injury pose significant public health problems, and violence is a leading cause of death and injury worldwide. ${ }^{1}$ There are over 700000 hospital admissions for accidental and violent injuries each year in England, ${ }^{2}$ and $9.2 \%$ of injuries occur through violence, ${ }^{3}$ with higher rates in metropolitan hospitals, ${ }^{4}$ in men and those aged 16-25 years. $^{5}$

\section{Strengths and limitations of this study}

This prospective study accessed a unique and hardto-reach urban sample of injured patients, many of whom would typically resist engagement with research and health services.

- It provides local-level information in a field where prevalences and risk factors vary considerably.

- The significant differences in follow-up participant characteristics pose problems; however, the statistical approach minimised the detrimental effects of this bias.

- Data on severity of injury were not available for all participants and could not be included in analyses. However, findings from other studies do not support an association between injury severity and posttraumatic stress disorder, suggesting injury severity would not have been an important confounder.

- The modest sample size prevented further adjustments to the model, such as ethnicity or suspected gang violence.

There is currently no routine assessment of psychological symptoms in trauma settings, and symptoms of psychological distress are rarely identified by clinical staff. ${ }^{6}$ However, traumatic injuries have psychological as well as physical consequences. ${ }^{89}$ US studies have reported high rates of psychological distress following trauma such as post-traumatic stress disorder (PTSD) and depression. ${ }^{10-13}$ PTSD can occur following exposure to, or witnessing, traumatic events such as death, serious injury or sexual violence. Post-traumatic stress symptoms (PTSS) include disturbing flashbacks, avoiding reminders, feelings of alienation and blame, and hyperarousal and reactivity, which persist for at least a month. Acute symptoms within the first month following trauma are recognised as acute stress disorder. Depression is a mood disorder characterised by depressed mood or loss of interest or pleasure with neurovegetative and cognitive symptoms and significant impairment. 
The prevalence of psychological distress following traumatic injury varies widely in different patient populations and countries, and there are few data available on UK rates. ${ }^{14}$ An international review, which included one study of motor vehicle collision patients in the UK, reported PTSS rates between $17.5 \%$ and $42 \%$ up to 6 months post injury; the range was greater still at 12 months, ranging from $2 \%$ to $36 \% .{ }^{15}$ Longitudinal studies show that PTSS prevalence falls over time. ${ }^{1516}$ American and Australian studies report rates of depressive symptoms ranging from $60 \%$ at baseline ${ }^{12}$ to $31 \%$ at 6 months, ${ }^{10} 12$ with rates at 1 year between $9 \%$ and $16 \% .^{813}$ The variation in prevalence is likely due to differences in location, nature of injury and demographic profile. Although one UK study of non-violent injuries is in progress, ${ }^{14}$ more studies are needed to plan National Health Service (NHS) care.

\section{Vulnerability to violent injury}

Conflict in the world is increasing in wars and in civilian settings, through violent protests, football match violence, armed robbery and street gangs. Civilians injured through violence are at greater risk of PTSS and more persistent symptoms than those who experience non-violent injuries. ${ }^{8101718}$ However, there is conflicting evidence on whether violent injury is associated with depressive symptoms. ${ }^{10}{ }^{19}$ Better recognition and treatment of those at risk of psychological sequelae would improve their quality of life and functioning.

Certain groups are more vulnerable to violent injury, including socioeconomically deprived people, ethnic minorities and young men, ${ }^{420}$ and deprivation is often a determinant of violent injuries with violence being used to secure more resources or to protest about deprivation. ${ }^{21}$ Rates of both violence and poor mental health are high in deprived urban areas. ${ }^{22}$ For example, people in South East London have much higher rates of exposure to trauma than those in other European inner cities as well as higher rates of PTSS, mental disorder and substance abuse. ${ }^{23}{ }^{24}$ In Hackney, East London, 9\% of men report belonging to a gang compared with $1 \%$ across Britain ${ }^{25}$ and East London boroughs are among those with the highest deprivation in England. ${ }^{26}$ Hardto-reach groups - including ethnic minorities, survivors of violence, people living in disadvantaged areas, those with mental health problems and youths at risk of criminal and gang involvement - are under-researched ${ }^{27}$ and tend to resist engaging with researchers ${ }^{28}$ as well as health services. ${ }^{29}$

The variation in rates of psychological distress and the particular challenges in inner cities demonstrate the need for more 'local thinking' on mental health. ${ }^{24}$ In this study, we tested the hypothesis that violent injury is associated with both depressive symptoms and PTSS and assessed risk factors for persistence of PTSS and depressive symptoms in patients attending a teaching hospital and major trauma centre in East London.

\section{METHODS}

This was an observational cohort study of inpatients admitted following accidental or violent injury.

\section{Setting}

Recruitment took place at the Royal London Hospital between July 2012 and April 2014. Participants were identified from consecutive patients discussed at bi-weekly multidisciplinary meetings of the major trauma and oral and maxillofacial surgery teams.

\section{Participants}

The inclusion criteria were as follows: admitted as hospital inpatients under major trauma or oral and maxillofacial trauma, aged 18 years or more and English speaking. The exclusion criteria were active psychosis, admission following deliberate self-harm, under the influence of alcohol or illegal substances, cognitive impairment based on a Glasgow Coma Score (GCS) below 15 and on the advice of clinical staff.

All participants provided informed consent in writing. Baseline measures were collected in hospital with a follow-up postal questionnaire at 8 months. All measures were self-report questionnaires, and we used published thresholds to identify clinically significant symptoms.

\section{Measures}

Baseline PTSS were measured using the Acute Stress Disorder Scale, ${ }^{30}$ using a threshold of scores $\geq 56$, which the creators of the measure found to be the most accurate predictor of subsequently developing PTSD. Follow-up PTSS were measured using the PTSD Checklist-Specific version (PCL-S), ${ }^{31}$ with a threshold of scores $\geq 45$. A psychometric analysis of the PCL-S among civilian trauma patients identified this threshold as having the highest diagnostic efficiency. ${ }^{31}$ Depressive symptoms at baseline and follow-up were measured using the Hospital Anxiety and Depression Scale (HADS), ${ }^{32}$ with a threshold of scores $\geq 8$ on the depression subscale. This threshold has been widely used and reported to have good sensitivity for identifying psychiatric morbidity. ${ }^{13} 3334$ Mechanism of injury was established from clinical information and provided a binary exposure variable of violent or accidental injury. Injury Severity Scores were collected from clinical records in major trauma but were not available for oral and maxillofacial trauma patients, and therefore could not be used in analyses. Demographic information was also collected.

\section{Statistical analysis}

Using previous findings on trauma survivors, ${ }^{35}$ it was calculated that a sample size of 67 in each group was required to test the hypothesis that mean scores on the PCL-S would be at least five points higher among participants injured through violence than among those injured accidentally. Calculations used a two-sided significance of 0.05 and a power of 0.9. Smaller sample sizes were required for the HADS. Higher numbers were sought at 
baseline because of anticipated difficulties in following up participants.

Sensitivity analyses used univariate logistic regressions to explore differences in follow-up. To understand simple associations in the data, we used $\chi^{2}$ tests and univariate logistic regressions. To test the longitudinal hypotheses, we used logistic multilevel models for repeated measures, with bootstrapping to produce more robust confidence intervals. Multilevel models allowed all participants' questionnaires to be included in the final statistical models whether participants had contributed to one or both waves, thus increasing statistical power. Missing data were not imputed. Outcomes for PTSS and depressive symptoms were assessed separately. When adjusting multilevel models, they were subjected to a likelihood ratio test after estimation to ensure optimal modelling of the variation.

We considered $p$ values less than 0.05 to be statistically significant. Statistical analyses were carried out using Stata statistical software (V.14). Power calculations were carried out using $G^{*}$ Power (V.3.1.7).

\section{RESULTS}

\section{Description of the data}

Of 829 patients admitted to the ward during the study period (July 2012 to April 2014), 467 met the study criteria. Of these 467, 225 patients (48.2\%) consented and were recruited to the study, $219(46.9 \%)$ of whom provided usable baseline data. Baseline measures were collected within 21 days after injury (mean days 4.27, 95\% CI 3.72 to 4.82). The main reason patients were excluded was a lack of an opportunity to approach patients due to surgical or rehabilitation procedures, or excessive pain or nausea $(22.9 \%, \mathrm{n}=190)$. Recruitment to the study did not differ by age or gender.

Of the 219 baseline participants, 109 (49.8\%) responded to follow-up at 8 months (mean days 228.23, 95\% CI 218.18 to 238.28), providing a total of 328 questionnaires for use in multilevel models. Reasons for loss to follow-up were not known.

There were significant group differences in those who did follow-up. Participants injured through interpersonal violence were significantly less likely to respond to follow-up (OR $0.29,95 \%$ CI 0.16 to 0.52 ), as were those with clinically significant PTSS (OR $0.36,95 \%$ CI 0.19 to 0.67 ) or depressive symptoms (OR $0.40,95 \%$ CI 0.22 to 0.72 ) at baseline.

\section{Sample characteristics}

Participants were predominantly men and young; over a third of participants had been injured through interpersonal violence (table 1 ).

Violent injury was more common among young, male and ethnic minority groups. Among the violently injured group, $34(44.7 \%)$ had been injured through suspected gang violence.
Table 1 Proportion of the sample injured violently, overall and within each demographic group

\begin{tabular}{ll}
\hline Demographic characteristic & Violent injury/total (\%) \\
\hline Total sample & $76 / 219(34.7)$ \\
\hline Gender & \\
\hline Male & $66 / 166(39.8)$ \\
\hline Female & $10 / 53(18.9)$ \\
\hline Age (years) & \\
\hline $18-25$ & $29 / 57(50.9)$ \\
\hline $26-35$ & $25 / 59(42.4)$ \\
\hline $36-45$ & $16 / 43(37.2)$ \\
\hline $46-65$ & $5 / 42(11.9)$ \\
\hline $66+$ & $1 / 18(5.6)$ \\
\hline Ethnicity & \\
\hline White, white British & $40 / 163(24.5)$ \\
\hline Black, black British & $18 / 23(78.3)$ \\
\hline Asian, Asian British & $9 / 17(52.9)$ \\
\hline Mixed, multiple, other & $9 / 16(56.3)$ \\
\hline
\end{tabular}

\section{Outcome data}

More than one quarter of participants reported PTSS, both among all baseline participants and among those responding at 8 months (figure 1). PTSS were more common after violent injury. Exact values are provided in online supplementary table 1 .

Almost one-third of participants reported depressive symptoms at baseline and at 8 months (figure 2). Those injured violently were more likely to have depressive symptoms. Exact values are provided in online supplementary table 2 .

\section{Main results}

In longitudinal models, violent injury significantly increased the odds of PTSS (unadjusted OR 6.41, 95\% CI 2.05 to 20.04; adjusted for age and gender OR 6.27, 95\% CI 1.90 to 20.66) and depressive symptoms (unadjusted OR 3.47, 95\% CI 1.26 to 9.57; adjusted for age and gender OR $3.12,95 \%$ CI 1.08 to 8.99 ).

\section{DISCUSSION}

\section{Principal findings}

This is the first UK prospective study of the persistence of psychological distress in people admitted with injuries to an inner city major trauma centre. The prevalence of both PTSS and depressive symptoms was high at baseline and follow-up, with over a quarter of participants experiencing clinically significant symptoms of PTSS and up to a third reporting clinically significant symptoms of depression. These figures are likely to be underestimates at follow up, as follow-up rates among those with psychological distress were lower. These rates are substantially higher than the $5.5 \%$ prevalence of PTSD in a London community sample ${ }^{23}$ and the $11.4 \%$ prevalence of 


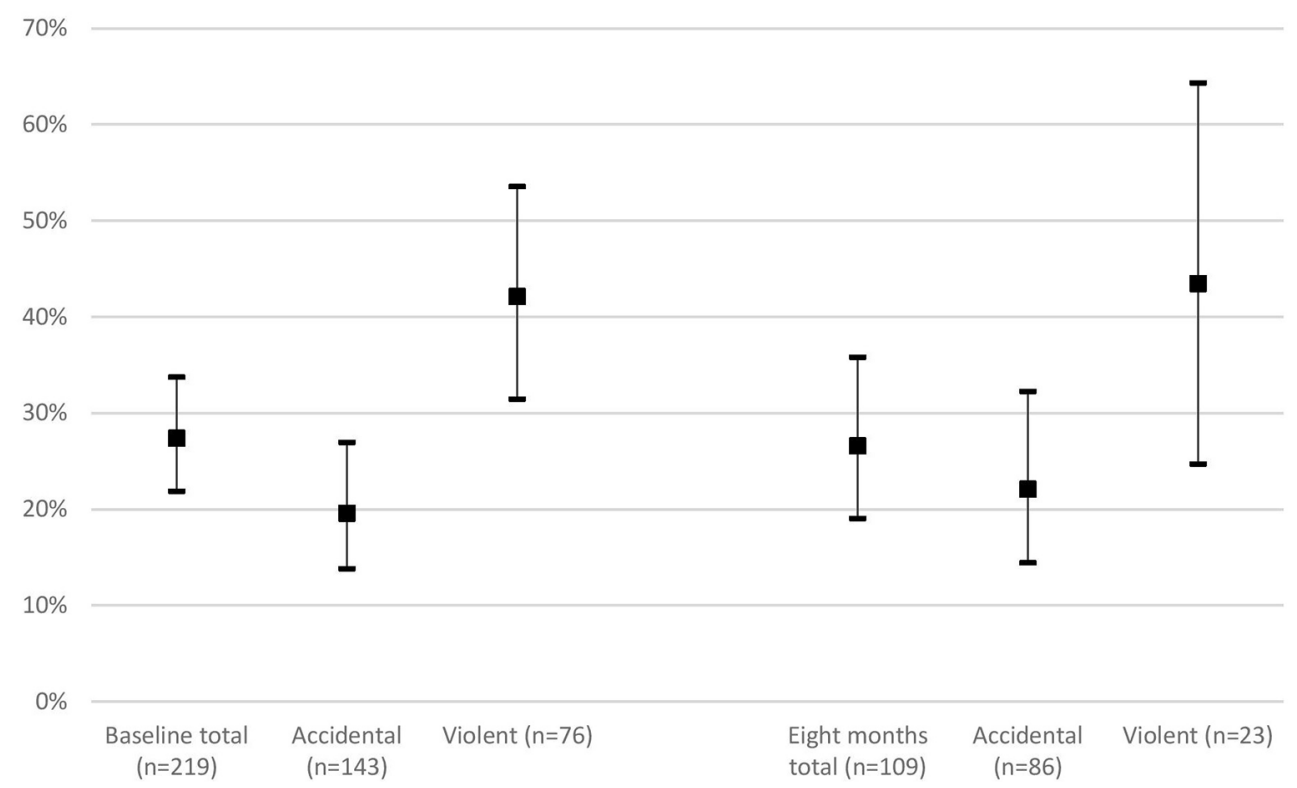

Figure 1 Prevalence of clinically significant PTSS at baseline and 8 months, $95 \% \mathrm{Cl}$. Threshold: ASDS $\geq 56$ at baseline and PCL-S $\geq 44$ at 8 months. ASDS, Acute Stress Disorder Scale; PCL-S, PTSD Checklist-Specific version; PTSS, post-traumatic stress symptoms.

depressive symptoms in the UK general population. ${ }^{36} \mathrm{~A}$ large proportion of participants in this study represent a group that is hard to engage in follow-up and into research studies. The sample comprised predominantly young men, and over a third of participants had been injured through interpersonal violence. Violent injury was more common among young, male and ethnic minority groups, and $44.7 \%$ of these individuals had been injured through suspected gang violence.

Previous studies in other countries have reported that rates of psychological distress following injury decrease over time. ${ }^{1516}$ However, in this population, symptoms persisted, and this may be partly due to the high proportion of participants injured through violence, as PTSS have been shown to remain high among victims of violence. ${ }^{818}$ We found that the prevalence of depressive symptoms in the overall sample also remained high, which has not been described previously. Those injured violently may have had ongoing experiences of violence, contributing to the persistence of distress.

Violent injury was a significant risk factor for both PTSS and depressive symptoms, increasing the odds of PTSS by a factor of six (OR 6.27, 95\% CI 1.90 to 20.66) and the odds of depressive symptoms by a factor of

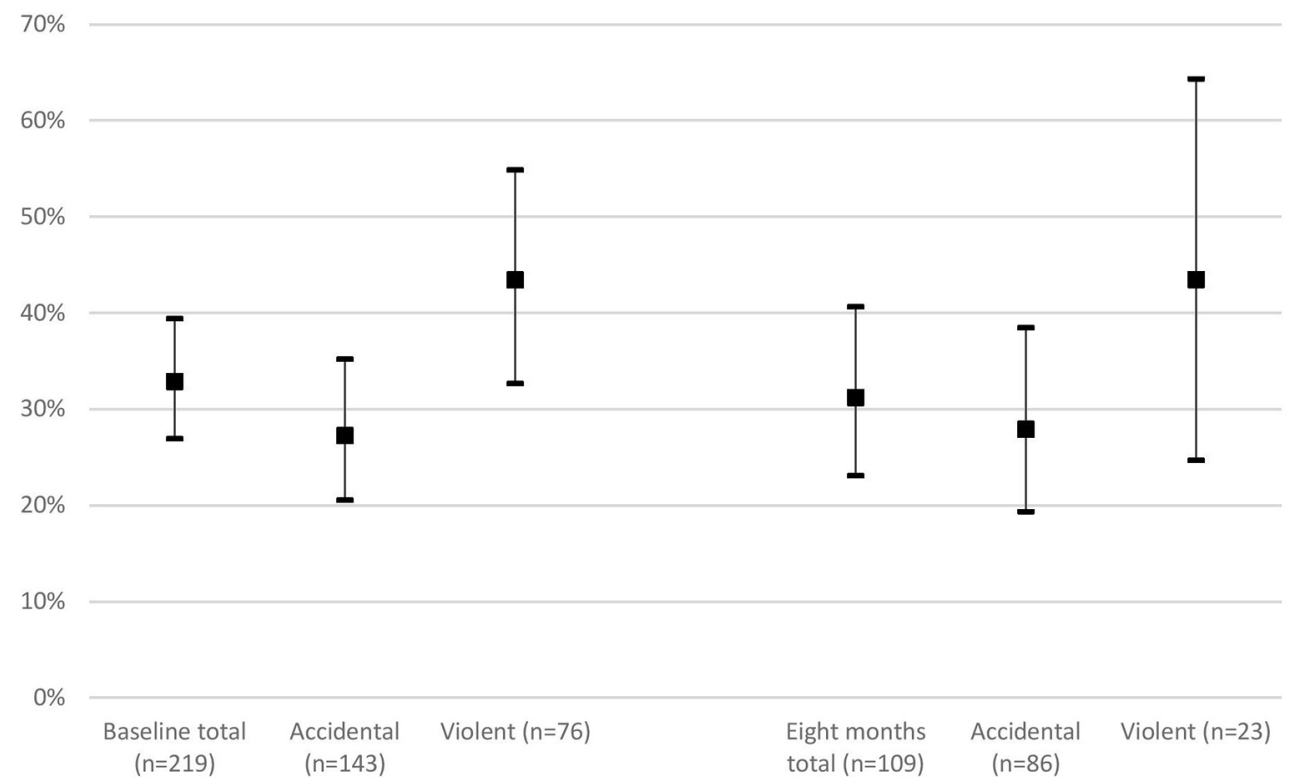

Figure 2 Prevalence of clinically significant depressive symptoms at baseline and 8 months, $95 \% \mathrm{Cl}$. Threshold: HADS-D $\geq 8$. HADS, Hospital Anxiety and Depression Scale . 
three (OR 3.12, 95\% CI 1.08 to 8.99). This increased risk of depressive symptoms following violent injury accords with one previous study. ${ }^{19}$

The sample included in this study provides a unique insight into the psychological needs of trauma patients in an East London hospital setting, many of whom are hard to reach. There were limitations in follow-up; however, this suggests that the prevalences reported at follow-up are likely to be an underestimate. This reinforces the need for routine assessment, intervention and signposting to support services in this population. It was not possible to use a clinical interview to confirm suspected psychiatric diagnoses. Further limitations include the inability to consider further variables in the analyses, such as severity of injury, experiences of trauma following discharge, ethnicity or suspected gang violence.

\section{Implications}

Given the high prevalence and persistence of distress in injury victims, there are clearly unidentified and unmet needs. In the high-pressure environment of trauma care, and in longer-term recovery from trauma, remarkably little attention is paid to mental health. NHS guidelines favour 'watchful waiting' for PTSS, with a follow-up at 1 month. However, the present findings suggest that early identification and intervention may be essential in some cases. This concurs with the suggestions of others studying trauma. ${ }^{37} 38$

Traumatic injury patients, including those with significant psychological symptoms, often lack insight into their conditions ${ }^{39}$ and can struggle to access counselling services. ${ }^{40}$ This puts a greater onus on healthcare workers to identify individuals at risk. ${ }^{6}$ Trauma settings need appropriate staff to assess patients' psychological needs and to initiate the delivery of care.

Stereotyped attitudes to trauma patients may create a further barrier to psychological care, with some staff in primary and secondary care believing that patients are themselves responsible for their injuries and that they do not merit psychological support. ${ }^{40}$ Furthermore, trauma healthcare workers in the UK report that the environment is not conducive to forming therapeutic relationships and that there is a gap between the ideal, compassionate care they would like to provide and the time-pressured reality. ${ }^{42}$ Gaps can occur in the transfer from secondary to primary care, where there is a need for continuity. ${ }^{40} 43$

Young people involved in gangs are likely to have poor experiences of healthcare as well as educational and social care systems. ${ }^{27}$ Trauma care is one of the key contact points within these systems where intervention may be possible, and it has been suggested that, in areas where gang activity is common, all individuals being treated by health services should be asked about gang membership. ${ }^{25}$ Hospital admission may, thus, provide a unique opportunity for intervention. An American intervention targeted hospitalised teenagers with evidence of violent behaviour and alcohol use: a brief hospital intervention improved violent behaviour and reduced alcohol use at follow-up. ${ }^{44}$ Such initiatives can be highly effective and could help seize unique 'teachable moments'.

Acknowledgements The authors acknowledge the support of the Centre for Trauma Sciences at Queen Mary University of London for enabling fieldwork to be undertaken.

Contributors ER participated in the design, data collection, data analysis and manuscript preparation. KB participated in the design, data analysis and manuscript preparation. MS participated in data analysis. IH participated in the receipt of funding, design and data collection. AK participated in the receipt of funding, design, data collection and manuscript preparation. All authors contributed to manuscript development and approved the final version and agree to be accountable for all aspects of the work.

Funding This work was supported by The Facial Surgery Research FoundationSaving Faces.

\section{Competing interests None declared.}

Ethics approval National Research Ethics Service (NRES), Camberwell St Giles Committee.

Provenance and peer review Not commissioned; externally peer reviewed. Data sharing statement № additional data available.

Open Access This is an Open Access article distributed in accordance with the Creative Commons Attribution Non Commercial (CC BY-NC 4.0) license, which permits others to distribute, remix, adapt, build upon this work non-commercially, and license their derivative works on different terms, provided the original work is properly cited and the use is non-commercial. See: http://creativecommons.org/ licenses/by-nc/4.0/

(c) Article author(s) (or their employer(s) unless otherwise stated in the text of the article) 2017. All rights reserved. No commercial use is permitted unless otherwise expressly granted.

\section{REFERENCES}

1. Krug EG, Mercy JA, Dahlberg LL, et al. World report on violence and health. Biomedica 2002;22(Suppl 2):327-36.

2. Hospital Episode Statistics: admitted Patient Care, England 2014-2015: external causes, 2015:1-34. http://www.hscic.gov.uk/ catalogue/PUB19124 (accessed 4 Apr 2015).

3. NCEPOD. Trauma: who cares? A Report of the National Confidential Enquiry Into Patient Outcome and Death, 2007. www.ncepod.org.uk/ 2007report2/Downloads/SIP_report.pdf (accessed 20 May 2014).

4. Hutchison IL, Magennis P, Shepherd JP, et al. The BAOMS United Kingdom survey of facial injuries part 1: aetiology and the association with alcohol consumption. Br J of Oral Maxillofac Surg 1998;36:3-13.

5. Morse A, Fisher A, Ross C. Major trauma care in England. London, 2010. www.nao.org.uk/trauma2010. (accessed 20 May 2014).

6. Bolduc A, Hwang B, Hogan C, et al. Identification and referral of patients at risk for Post-traumatic stress disorder: a Literature Review and retrospective analysis. Am Surg 2015;81:904-8.

7. Islam S, Hooi H, Hoffman GR. Presence of pre-existing psychological comorbidity in a group of facially injured patients: a preliminary investigation. J Oral Maxillofac Surg 2009;67:1889-94.

8. Bryant RA, O'Donnell ML, Creamer M, et al. The psychiatric sequelae of traumatic injury. Am J Psychiatry 2010;167:312-20.

9. Craig A, Tran Y, Guest R, et al. Psychological impact of injuries sustained in motor vehicle crashes: systematic review and metaanalysis. BMJ Open 2016;6:e011993.

10. Shih R, Schell T. Prevalence of PTSD and Major depression following trauma-center hospitalization. J Trauma 2010;69:1560-6.

11. Zatzick DF, Rivara FP, Nathens AB, et al. A Nationwide US study of post-traumatic stress after hospitalization for Physical injury. Psychol Med 2007;37:1469-80.

12. Holbrook TL, Anderson JP, Sieber WJ, et al. Outcome after Major trauma: discharge and 6-month follow-up results from the Trauma Recovery Project. J Trauma 1998;45.

13. Schnyder $\mathrm{U}$, Moergeli $\mathrm{H}$, Trentz $\mathrm{O}$, et al. Prediction of psychiatric morbidity in severely injured accident victims at one-year follow-up. Am J Respir Crit Care Med 2001;164:653-6.

14. Kendrick D, O'Brien C, Christie N, et al. The impact of injuries study. multicentre study assessing physical, psychological, social and occupational functioning post injury-a protocol. BMC Public Health 2011;11:963. 
15. O'Donnell ML, Creamer M, Bryant RA, et al. Posttraumatic disorders following injury: an empirical and methodological review. Clin Psychol Rev 2003;23:587-603.

16. Haagsma JA, Polinder S, Toet $\mathrm{H}$, et al. Beyond the neglect of psychological consequences: post-traumatic stress disorder increases the non-fatal burden of injury by more than $50 \%$. Inj Prev 2011;17:A247.

17. Lim BH, Adams LA, Lilly MM. Self-worth as a mediator between attachment and posttraumatic stress in interpersonal trauma. $J$ Interpers Violence 2012;27:2039-61.

18. Johansen VA, Wahl AK, Weisaeth L. Assaulted victims of nondomestic violence in Norway-injury, crime characteristics and emotions during the assault. Scand J Caring Sci 2008;22:445-54

19. deRoon-Cassini TA, Mancini AD, Rusch MD, et al. Psychopathology and resilience following traumatic injury: a latent growth mixture model analysis. Rehabil Psychol 2010;55:1-11.

20. Lee KH. Interpersonal violence and facial fractures. J Oral Maxillofac Surg 2009;67:1878-83.

21. Herrenkohl TI, Maguin E, Hill KG, et al. Developmental risk factors for youth violence. J Adolesc Health 2000;26:176-86.

22. Hatch SL, Frissa S, Verdecchia M, et al. Identifying sociodemographic and socioeconomic determinants of health inequalities in a diverse London community: the South East London Community Health (SELCoH) study. BMC Public Health 2011;11:861.

23. Frissa S, Hatch SL, Gazard B, et al. Trauma and current symptoms of PTSD in a South East London community. Soc Psychiatry Psychiatr Epidemiol 2013;48:1199-209.

24. Hatch SL, Woodhead C, Frissa S, et al. Importance of thinking locally for Mental Health: data from Cross-Sectional surveys representing South East London and England. PLoS One 2012;7:e48012.

25. Coid JW, Ullrich S, Keers R, et al. Gang membership, violence, and psychiatric morbidity. Am J Psychiatry 2013;170:985-93.

26. McLennan D, Barnes $\mathrm{H}$, Noble $\mathrm{M}$, et al; The English Indices of Deprivation 2010. London, 2010.

27. Bonevski B, Randell M, Paul C, et al. Reaching the hard-to-reach: a systematic review of strategies for improving health and medical research with socially disadvantaged groups. BMC Med Res Methodol 2014;14:42.

28. Ellard-Gray A, Jeffrey NK, Choubak M, et al. Finding the Hidden Participant: solutions for Recruiting Hidden, Hard-to-Reach, and vulnerable populations. Int J Qual Methods 2015;14:1-10.

29. Flanagan SM, Hancock B. 'Reaching the hard to reach'--lessons learned from the VCS (voluntary and community Sector). A qualitative study. BMC Health Serv Res 2010;10:92.

30. Bryant RA, Moulds ML, Guthrie RM. Acute stress disorder Scale: a self-report measure of acute stress disorder. Psychol Assess 2000;12:61-8.
31. Blanchard EB, Jones-Alexander J, Buckley TC, et al. Psychometric properties of the PTSD checklist (PCL). Behav Res Ther 1996;34:669-73.

32. Zigmond AS, Snaith RP. The hospital anxiety and depression scale. Acta Psychiatr Scand 1983;67:361-70.

33. O'Donnell ML, Creamer MC, Parslow R, et al. A predictive screening index for posttraumatic stress disorder and depression following traumatic injury. J Consult Clin Psychol 2008;76:923-32.

34. Sen P, Ross N, Rogers S. Recovering maxillofacial trauma patients: the hidden problems. J Wound Care 2001;10:53-7.

35. Zatzick D, Roy-Byrne P, Russo J, et al. A randomized effectiveness trial of stepped collaborative care for acutely injured trauma survivors. Arch Gen Psychiatry 2004;61:498-506.

36. Crawford JR, Henry JD, Crombie C, et al. Normative data for the HADS from a large non-clinical sample. Br J Clin Psychol 2001;40:429-34.

37. Alarcon LH, Germain A, Clontz AS, et al. Predictors of acute posttraumatic stress disorder symptoms following civilian trauma: highest incidence and severity of symptoms after assault. J Trauma Acute Care Surg 2012;72:629-35.

38. Stephens KA, Sue S, Roy-Byrne P, et al. Ethnoracial variations in acute PTSD symptoms among hospitalized survivors of traumatic injury. J Trauma Stress 2010;23:n/a-92.

39. Wong EC, Kennedy D, Marshall GN, et al. Making sense of posttraumatic stress disorder: illness perceptions among traumatic Injury Survivors. Psychol Trauma 2011;3:67-76.

40. Christie N, Beckett K, Earthy S, et al. Seeking support after hospitalisation for injury: a nested qualitative study of the role of primary care. Br J Gen Pract 2016;66:e24-e31.

41. Shepherd JP. Victims of personal violence: the relevance of Symonds' Model of Psychological Response and Loss-Theory. Br J Soc Work 1990;20:309-32. http://bjsw.oxfordjournals.org/content/ 20/4/309.short.

42. Beckett K, Earthy S, Sleney J, et al. Providing effective trauma care: the potential for service provider views to enhance the quality of care (qualitative study nested within a multicentre longitudinal quantitative study). BMJ Open 2014;4:e005668.

43. Kellezi B, Beckett K, Earthy S, et al. Understanding and meeting information needs following unintentional injury: comparing the accounts of patients, carers and service providers. Injury 2015;46:564-71.

44. Walton MA, Chermack ST, Shope JT, et al. Effects of a brief intervention for reducing violence and alcohol misuse among adolescents: a randomized controlled trial. JAMA 2010;304:527-35. 